\title{
The Spread of the Pandemic of Social Media Panic during the COVID-19 Outbreak
}

\author{
Eqbal Radwan ${ }^{1,2 *}$, Afnan Radwan ${ }^{3}$
}

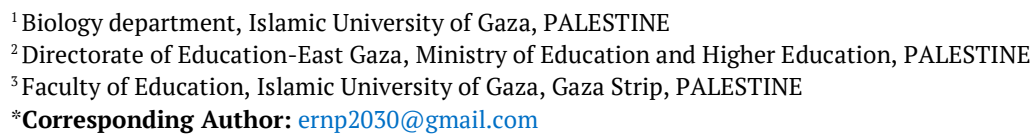

Citation: Radwan, E. and Radwan, A. (2020). The Spread of the Pandemic of Social Media Panic during the COVID-19 Outbreak. European Journal of Environment and Public Health, 4(2), em0044. https://doi.org/10.29333/ejeph/8277

ARTICLE INFO

Received: 15 April 2020

Accepted: 13 May 2020

\begin{abstract}
The outbreak of novel COVID-19 has opened up different issues for social media including the life-endangering consequences of supposed cures, misleading rumors, and conspiracy theories about the origin of coronavirus. These dangerous rumors circulated the world and thus paired with racism and mass fearmongering all closely linked to the new "Infomedia" systems of the present century characterized by the multiplicity of means of communication between people especially platforms of social media. The sharing of misinformation has an influence beyond the harm of the coronavirus itself. Many posts were seen related to treatments that are not proven, techniques to mitigate exposure, and infection that are either not proven and/or filled with a lot of misleading information, and instruction for individuals to stock up on supplies and food. Taking into account the present situation, there is an important need to consider and assess the awareness of the public towards the dangerous impact of the spread of misinformation in the time of the COVID-19 outbreak.
\end{abstract}

Keywords: COVID-19, social media panic, pandemic, misinformation

Dear Editor,

During the current days, after the outbreak of a new coronavirus (COVID-19) among people around the world, an increasing amount of information and concerns are influencing global mental health. International health organizations, global and local media, decision-makers, virologists and epidemiologists put out recommendations, discussions, results, information, and updates on the outbreak of COVID-19 pandemic (Torales et al., 2020). As of May 10, 2020 , there were a total of $3,925,815$ confirmed cases and 274,488 confirmed deaths around the world.

The outbreak of novel COVID-19 has opened up different issues for social media including the life-endangering consequences of supposed cures, misleading rumors, and conspiracy theories about the origin of coronavirus. Be it domestic or foreign in origin, the misinformation threat seemed familiar, perhaps even manageable. So far, almost 200 rumors and myths have debunked about the virus. These dangerous rumors circulated the world and thus paired with racism and mass fearmongering all closely linked to the new "Infomedia" systems of the present century characterized by the multiplicity of means of communication between people especially platforms of social media. With the popularity of the internet and smartphones, information on COVID-19 spread rapidly among the public on social media. On social media, some people have shared false claims because they failed to think about whether the content was reliable. The sharing of misinformation has an influence beyond the harm of the coronavirus itself. Many posts were seen related to treatments that are not proven, techniques to mitigate exposure and infection that are either not proven and/or filled with a lot of misleading information, and instruction for individuals to stock up on supplies and food.

A remarkable particularity of the present crisis is the coincidence of virality and virology: not only did the virus itself spread very rapidly but so did the information and misinformation related to the outbreak of pandemic in the globe. As a result, panic, fear, and anxiety -as a natural reaction- were generated among the people especially children, women, and older persons (McCauley et al., 2013; Larson, 2018). According to Wilson and Chen (2020), social media panic spread faster than the COVID-19 outbreak. In many ways, we could identify a metonymic principle, where the images related to the physical epicenters crisis, especially the archaic imagery of quarantine, were usually related to people and places connected with this archaic imagery as Chinese tourists, goods, and restaurants leading to increase the rate of distrust and racism (King, 2015). According to WHO, misinformation on the coronavirus leading to the spread of 
disruption, panic, and fear, and thus hampering the contain of COVID-19 pandemic.

Media reporting and public sentiments may have a significant effect on the various sectors with regard to making the right decision at the right time on discontinuing certain services disproportionate to the true public health need (Depoux et al., 2020). Travel and movement restrictions are one of the most examples of these decisions, and we need urgently to identify the impact of social media on such measures that carry enormous economic damage. The Spatiotemporal variability in the discussions on various social media, specifically Facebook, is often not in line with the spatiotemporal occurrence and severity of the outbreak of COVID-19 pandemic.

There are two types of the danger posed by misinformation on the virus: that it could incite panic, and the potential for persons to do harmful things in hope of curing the illness. In the present day, we need urgently to combat the pandemic of social media panic and minimize their effect on the mental health of people. This measure has a significant influence in the time of the outbreak of COVID-19 besides the adherence of the public-health measures (The Lancet, 2020). To achieve this purpose, it is important to carry out spatiotemporal analyses of the discourse and its disassociation or association with the current epidemiological situation. Therefore, this will allow spatiotemporal intervention campaigns and targeted communication to be executed by public health authorities (Depoux et al., 2020). In these critical days, we need to urgently determine, evaluate and respond to public rumors, values, attitudes, perceptions, and behaviors related to COVID-19 and control measures.

The creation of an interactive platform to display real-time alerts of concerns, rumors, and misinformation regarding the outbreak of COVID-19 pandemic in the globe will help the officials and relevant stakeholders to respond urgently to mitigate the impact of misinformation on the public as well as providing the citizens with $t$ concise, precise and real information related to COVID-19. At this time in spite of having no nonpharmaceutical interventions to combat the outbreak of COVID-19 pandemic, we have alternative tools to contain this pandemic as the movement restrictions, health isolation, quarantine, social distancing and community containment (Wilder-Smith and Freedman, 2020). In this regard, all types of social media should be harnessed properly to enhance the needed mobilization of the public to adherence quarantine procedures, minimize the spread of fears and uncertainty to the lowest level, and reinforce public trust in public health measures. By collaborating with the public and by providing accurate guidance for public participation, we can ensure the efficacy of quarantine measures during the outbreak of epidemics among the communities (Ding, 2014). Social media have Immediate positive impact on the public if only was used correctly. Placed authoritative coronavirus information, and intensifying the efforts to remove harmful content will enhance the public health and help to contain the outbreak of COVID-19. The content rated to false rumors about COVID-19 should not be shared so that no one can see it. Analyses of comments, discussions, chats, and messages on social media with respect to the current status of the epidemic can result in real-time maps which could be used as a key source of information on the place of intervening with main communication campaigns (Depoux et al., 2020).

The major component for the positive influence of social media is concentrating on the exchange of corrected and balanced information and positioning of the public in a proper environment that presented the necessary health information and thus at the end enables the public to contain the COVID19 pandemic. In addition, some specialists suggest that digital toolkit could be employed to build future tools for rapid engagement and deployment where socio-cultural and multilingual responses are strongly required. In this regard, WHO has created a webpage to present the right information as well as to correct misinformation about the COVID-19 outbreak. The outbreak of social media panic can only be fought with real, right and concise information (The, 2020).

Social media should be harnessed to enhance and support the public health response. For example, in the Gaza Strip, during the movement restrictions period, quarantine or isolation, it is necessary to utilize social media wisely where social media give a good opportunity to communicate with others, to express the reasons for quarantine, as well as to provide reassurance and practical advice to pre-empt panic and misleading rumors. During the movement restriction period or quarantine of the public and during the isolation of the infected people, the modern telecommunication, especially social media, can overcome the social distancing constraints. In addition, it provides mental health support resources and solidarity with those people in a lock-down situation. The pro-active and on-going analysis of global online messages, discussions, and conversations could provide an overview to evaluate the potential changes in the attitudes, trends, behavior, and awareness of people during the outbreak of COVID-19. With this regard, during the outbreak of Ebola in the past, the implementation of a rumors management strategy, social media monitoring, and enhancement of tools and mobile technologies led to promote the acceptance of new Ebola vaccines as well as contain the outbreak this virus among the public.

For the present COVID-19 crisis, we call for the global creation of an information-sharing system, depending on data from the platforms of social media in different languages to ensure the arrival of all interested people to this system. This procedure will enhance the ability of relevant stakeholders and public health authorities to respond to and understand the social dynamics of the rapid spread of information and misinformation about the outbreak of COVID-19 pandemic and the control measures to contain this virus. In addition, it will also reduce mass panic and unhelpful measures that stand against containing this pandemic.

\section{REFERENCES}

Atlani-Duault, L., Ward, J. K., Roy, M., Morin, C. and Wilson, A. (2020). Tracking online heroisation and blame in epidemics. Lancet Public Health, 5(3), e137-e138. https://doi.org/10.1016/S2468-2667(20)30033-5 
Depoux, A., Martin, S., Karafillakis, E., Preet, R., Wilder-Smith, A. and Larson, H. (2020). The pandemic of social media panic travels faster than the COVID-19 outbreak. Journal of Travel Medicine. https://doi.org/10.1093/jtm/taaa031

Ding, H. (2014). Transnational quarantine rhetorics: public mobilization in SARS and in H1N1 flu. J Med Humanit, 35(2), 191-210. https://doi.org/10.1007/s10912-014-92828

King, N. B. (2015). Mediating panic: The iconography of 'new'infectious threats, 1936-2009. Empires of panic: Epidemics and colonial anxieties, 181-202. https://doi.org/10.5790/hongkong/9789888208449.003.0008

Larson, H. J. (2018). The biggest pandemic risk? Viral misinformation. Nature, 562(7727), 309. https://doi.org/10.1038/d41586-018-07034-4

McCauley, M., Minsky, S. and Viswanath, K. (2013). The H1N1 pandemic: media frames, stigmatization and coping. BMC Public Health, 13, 1116. https://doi.org/10.1186/14712458-13-1116
The Lancet. (2020). COVID-19: fighting panic with information. $\quad$ Lancet, 337. https://doi.org/10.1016/S0140-6736(20)30379-2

Torales, J., O’Higgins, M., Castaldelli-Maia, J. M. and Ventriglio, A. (2020). The outbreak of COVID-19 coronavirus and its impact on global mental health. International Journal of Social Psychiatry, 0020764020915212. https://doi.org/10.1177/0020764020915212

Wilder-Smith, A. and Freedman, D. O. (2020). Isolation, quarantine, social distancing and community containment: pivotal role for old-style public health measures in the novel coronavirus (2019-nCoV) outbreak. J Travel Med. https://doi.org/10.1093/jtm/taaa020

Wilson, M. E. and Chen, L. H. (2020). Travelers Give Wings to Novel Coronavirus (2019- nCoV). J Travel Med. https://doi.org/10.1093/jtm/taaa015 